\title{
Topical oleaginous minocycline foam: efficacious delivery into skin layers
}

\begin{abstract}
Minocycline hydrochloride $(\mathrm{MCH})$ is a broad spectrum antibiotic of the tetracycline group that is extensively used to treat skin conditions such as acne and rosacea. Unfortunately, since this antibiotic is highly prone to degradation, no minocycline-containing topical product is currently available on the market. In this pilot study, $\mathrm{MCH}$ was incorporated into a novel oleaginous foam recently developed by Foamix Pharmaceuticals, Ltd. The product, coded FMX101, was produced in drug concentrations of $1 \% \mathrm{w} / \mathrm{w}$ or $4 \% \mathrm{w} / \mathrm{w}$. An in vitro porcine skin model was utilized to evaluate the extent of $\mathrm{MCH}$ penetration into the skin layers and compartments. The results indicated that topical foam administration allows MCH penetration that is sufficiently deep to treat most typical skin infections, acne and rosacea. Additional studies, using MALDI FTICR imaging and fluorescent microscopy techniques demonstrated visually the residence of $\mathrm{MCH}$ in the stratum corneum, the epidermis and the dermis and showed specific targeting to the pilosebaceous unit. The antibiotic foam caused virtually no trans-dermal drug absorption.
\end{abstract}

Volume 4 Issue 5 - 2017

\author{
Yohan Hazot, Tatyana Malinov, Elana Gazal, \\ Rita Keynan, Lenny Margulis, Dov Tamarkin \\ Foamix Pharmaceuticals Ltd, Israel
}

Correspondence: Dov Tamarkin, Foamix Pharmaceuticals Ltd, 2 Holzman Street, Weizmann-Science Park, Rehovot 76704 Israel, Tel + | 6175966026

Email dov.tamarkin@foamixpharma.com

Received: April 24, 2017| Published: May 03, 2017

Keywords: rosacea, epidermis, fluorescent microscopy, bacteriostatic, minocycline, oxidation, tetracyclines

Abbreviations: $\mathrm{MCH}, \quad$ minocycline hydrochloride; MALDI,matrix assisted laser desorption/ionization; FTICR,fourier transform ion cyclotron resonance; TEWL,transepidermal water loss; UPLC, ultra performance liquid chromatography; EDTA,ethylenediaminetetraacetic acid; HPLC,high-performance liquid chromatography

\section{Introduction}

Minocycline hydrochloride $(\mathrm{MCH})$ is a broad spectrum bacteriostatic antibiotic of the tetracycline family. The drug is used primarily to treat skin condition such as acne and rosacea, as well as skin infections such as infections impetigo. ${ }^{1}$ Although $\mathrm{MCH}$ is relatively stable in the solid state, like other tetracyclines, it extensively degrades upon contact with water and protic solvent. It is also sensitive to light and oxidation. For all these reasons, there is no topical product that contains minocycline - or indeed any tetracycline - currently available on the market. In fact, $\mathrm{MCH}$ is currently available only in the form of tablets and capsules that may cause multiple systemic side effects upon oral intake. ${ }^{1}$ As shown in Figure 1 , the antibiotic has a relatively high molecular weight of $457 \mathrm{Da}$ and therefore it is not expected to penetrate efficiently into or through the skin. However, its penetration can potentially be enhanced due to its relative hydrophobic nature in comparison to the other tetracyclines in pharmaceutical use. At $\mathrm{pH} 7$, minocycline shows a log distribution coefficient of -1.6 in aqueous buffer/trichloromethane. ${ }^{2}$

Within the field of topical drug delivery, recent years have witnessed growing interest in the design, development and usage of foam-based formulations. ${ }^{3-6}$ These foams are essentially gas-in-liquid dispersions, in which the gas volume fraction usually ranges between 0.5 and 0.9 . They are thermodynamically and mechanically unstable systems. Interestingly, foams have been shown to be generally preferred by patients over more conventional gels, creams and ointments. Subjects often describe foams as being more cosmetically elegant, aesthetically attractive and exhibiting superior spreading capabilities than other rival formulations. This was exemplified in a study involving 120 volunteers who assessed the usability profile of foams against a cream control. ${ }^{8}$ Foam was judged to be significantly superior to the cream in terms of ease of application, uniformity of spreading, subjective skin 'feel' as well as visual appearance. In a trial of 139 seborrheic dermatitis patients, it was found that foam vehicles were preferred over other traditional vehicles, irrespective of subject gender, age or ethnicity. ${ }^{9}$ Other trials have revealed similar findings. ${ }^{10}$

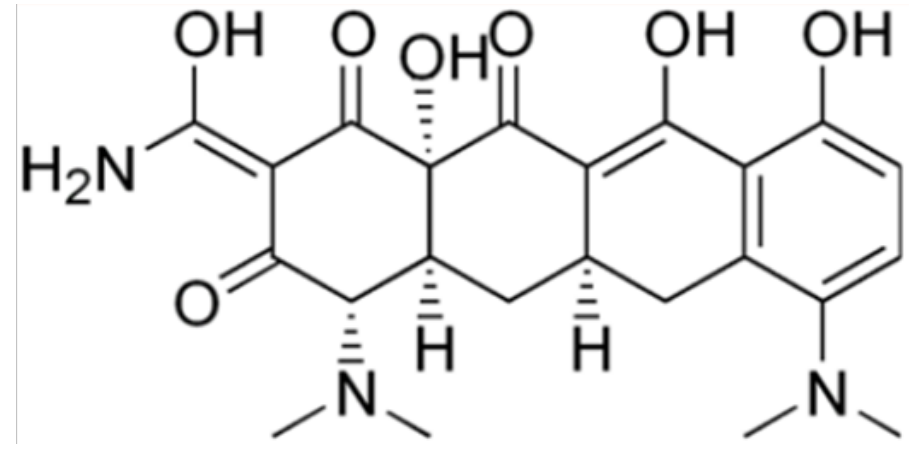

Figure I Structural Formula of Minocycline.

In the current study, we examined the skin deposition of $\mathrm{MCH}$ following its topical application in the form of a novel, oleaginous foam. The foam, coded FMX101, was developed recently by Foamix Pharmaceuticals, Ltd. (Rehovot, Israel). The foam vehicle consists of a diverse mixture of oil components, fatty alcohols, fatty acids and stabilizers. A blend of propane, butane and isobutane acts as propellant. In the present research, $\mathrm{MCH}$ was incorporated into this foam at concentrations of $1 \% \mathrm{w} / \mathrm{w}$ or $4 \% \mathrm{w} / \mathrm{w}$ (expressed as free base). A finite dose of $20 \mathrm{mg}$ of foam was used. The degree of $\mathrm{MCH}$ penetration into different skin strata and through the skin was assessed in an in vitro porcine skin model. The aim was to provide pilot data on the usage feasibility of this topical $\mathrm{MCH}$ formulation and its potential systemic effects. 


\section{Methods}

\section{Materials}

Ammonium oxalate (Analytical grade) and EDTA disodium (Pharma grade) were obtained from Sigma-Aldrich (St. Louis, MO). Water (ULC/MS grade) and Heptane (HPLC grade) were purchased from BioLab Ltd (Jerusalem, Israel). Acetonitrile (LC grade) and dimethylformamide were purchased from Merck (Darmstadt, Germany). Tetrahydrofuran (HPLC grade) was purchased from Acros Organics (Morris Plains, NJ). Micronized minocycline hydrochloride was provided by Hovione FarmaCiencia (Loures, Portugal).

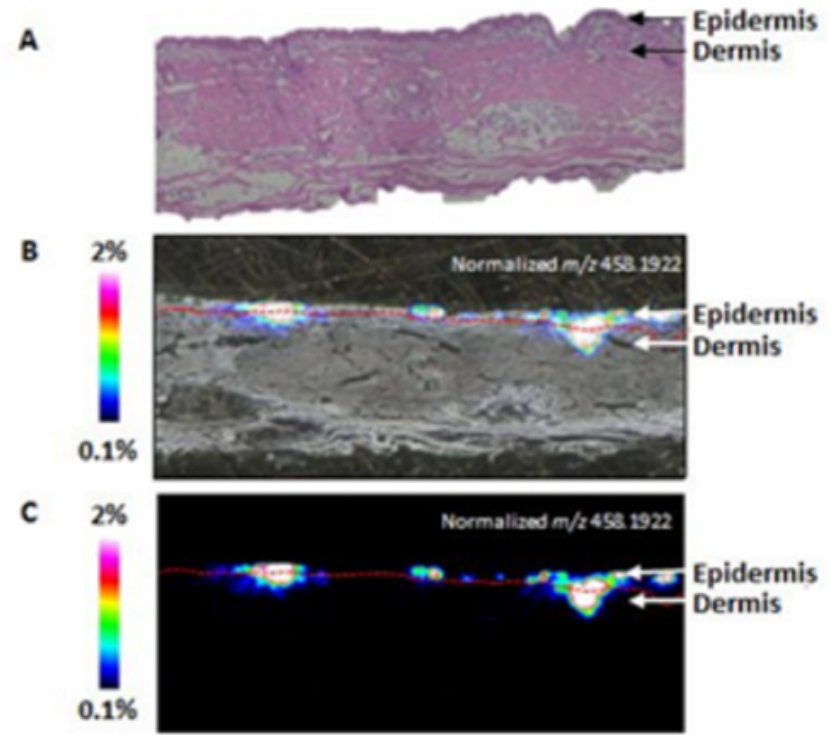

Figure 2 Molecular Distribution of Minocycline in Pig Ear Skin by 7T-MALDIFTICR Imaging.

A: H\&E staining performed on an adjacent tissue section.

B: Overlay between the optical image and Minocycline molecular distribution by MSI.

C: Minocycline molecular distribution by MSI.

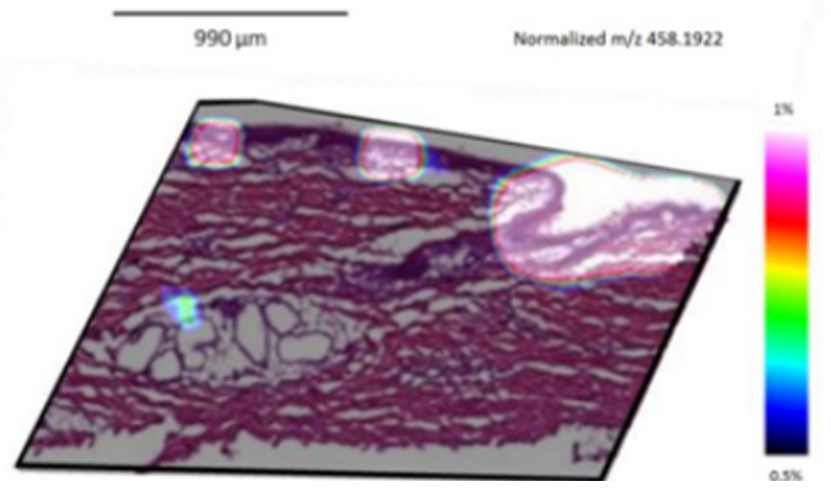

Figure 3 Molecular Distribution of Minocycline in Pig Ear Skin by 7T-MALDIFTICR Imaging.

The foam product FMX101 contained either $1 \%$ or $4 \% \mathrm{w} / \mathrm{w}$ micronized minocycline in a vehicle included of the following excipients, soybean oil, coconut oil, light mineral oil, cyclomethicone, cetostearyl alcohol, stearic acid, myristyl alcohol, hydrogenated castor oil, beeswax, stearyl alcohol and docosanol. The propellant comprised propane, butane and isobutane.

\section{Preparation of skin membranes}

Full-thickness porcine skin samples, derived from the ears of white pigs, were purchased from the Institute of Animal Research (Kibbutz Lahav, Israel). Each skin sample had dimensions of $\sim 4 \times 4 \mathrm{~cm}$ and was of $\sim 1.2 \mathrm{~mm}$ thickness. Upon arrival in the lab, the skin samples were visually checked for integrity and then stored in a frozen state $\left(-20^{\circ} \mathrm{C}\right)$. Immediately before each permeation study, the skin samples were thawed at room temperature for a $1 \mathrm{~h}$ period. The skins were cut into smaller samples that were suitable for mounting in the Franz cells.

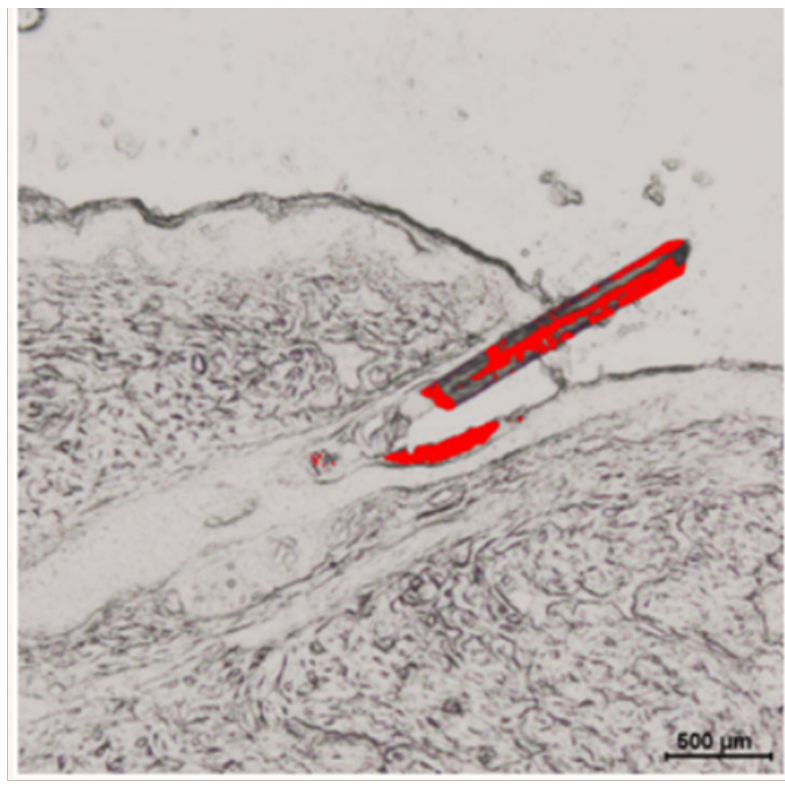

Figure 4 Minocycline penetrates the pilosebaceous unit, following topical application of FMXIOI to pig ear skin. Superimposed reflectance and fluorescent images demonstrate residence of the drug in the pilosebaceous unit, including the hair follicle and the sebaceous gland (red areas).

\section{TEWL measurements}

The barrier function of each skin sample was assessed by measuring its transepidermal water loss (TEWL). This was achieved by using a Tewameter ${ }^{\circledR}$ TM300 (Courage \&Khazaka GmbH, Cologne, Germany). Stable TEWL readings were recorded. Only skin pieces showing TEWL levels less than $15 \mathrm{~g} / \mathrm{h} \mathrm{m}^{2}$ were used in skin penetration studies.

\section{Permeation studies}

The hairs of each skin sample were gently clipped short with scissors taking care not to puncture or damage the tissue. The skins were gently rinsed in PBS ( $\mathrm{pH} 7.4$ ) for 20min. Subsequently, the skin samples were placed over the receptor compartment of Franz diffusion cells (PermeGear, Bethlehem PA) exhibiting a diffusionavailable surface area of $1.77 \mathrm{~cm}^{2}$ and a receptor cell volume of $14 \mathrm{ml}$. The receptor solution consisted of PBS ( $\mathrm{pH} 7.4)$. This solution was magnetically-stirred and maintained at $35^{\circ} \mathrm{C}$ by the use of a thermostatic water pump (Haake DC10, Karlsruhe, Germany) that circulated water through each chamber jacket. The cells were momentarily inverted in order to allow the escape of any air bubbles adhering to the skin underside. The permeation studies were initiated by depositing $20 \mathrm{mg}$ of minocycline foam (either $1 \%$ or $4 \% \mathrm{w} / \mathrm{w}$ ) in each donor cell and using a spatula to spread the foam evenly over the skin surface. Drug permeation was allowed to proceed for $24 \mathrm{~h}$. Due to the known inter-sample variation in porcine skin permeability, ${ }^{11}$ each experiment consisted of 6 replicates. 
Table I MCH amounts present within different skin compartments at $24 \mathrm{~h}$

\begin{tabular}{lll}
\hline & Minocycline foam I\% & Minocycline foam 4\% \\
\hline Unabsorbed residue & $168.22 \pm 6.66 \mu \mathrm{g}$ & $592.56 \pm 32.34 \mu \mathrm{g}$ \\
on surface & $95.04 \mu \mathrm{g} / \mathrm{cm}^{2}$ & $334.77 \mu \mathrm{g} / \mathrm{cm}^{2}$ \\
& $10.60 \pm 4.26 \mu \mathrm{g}$ & $105.41 \pm 24.98 \mu \mathrm{g}$ \\
Stratum corneum & $5.99 \mu \mathrm{g} / \mathrm{cm}^{2}$ & $59.55 \mu \mathrm{g} / \mathrm{cm}^{2}$ \\
& $0.78 \pm 0.09 \mu \mathrm{g}$ & $3.49 \pm 0.92 \mu \mathrm{g}$ \\
Viable skin & $0.44 \mu \mathrm{g} / \mathrm{cm}^{2}$ & $1.97 \mu \mathrm{g} / \mathrm{cm}^{2}$ \\
& $11.38 \pm 4.26 \mu \mathrm{g}$ & $108.90 \pm 24.95 \mu \mathrm{g}$ \\
Total skin & $6.43 \mu \mathrm{g} / \mathrm{cm}^{2}$ & $61.52 \mu \mathrm{g} / \mathrm{cm}^{2}$ \\
Receiver Fluid & 0 & 0 \\
\hline
\end{tabular}

Each value in $\mu g$ represents the mean \pm standard error of the mean.

Each value denoted in $\mu \mathrm{g} / \mathrm{cm}^{2}$ represents just the mean.

6 replicates were used throughout.

\section{Isolation of skin strata}

At $24 \mathrm{~h}$, the skin samples were removed from the diffusion cells and the different skin compartments were separated according to established methods. ${ }^{12}$ Firstly, unabsorbed surface residues of minocycline were collected by wiping each skin sample surface with filter paper as well as tape stripping the skin just once with a "Scotch Magic TM" adhesive tape (3M, St Paul, MN). The filter paper and tape were placed in a centrifuge tube containing heptane $(2 \mathrm{ml})$, $0.1 \mathrm{M}$ ammonium oxalate $(2 \mathrm{ml})$ and acetonitrile $(1 \mathrm{ml})$. Isolation of the stratum corneum was achieved by stripping each skin sample using 19 successive tapes. Nine tapes were collected in one centrifuge tube and ten additional tapes were subsequently placed in a second tube.The tubes were filled with a mixture of $0.1 \mathrm{M}$ ammonium oxalate $(1.3 \mathrm{ml})$ and acetonitrile $(0.7 \mathrm{ml})$, to dissolve and extract minocycline out of the tapes.

The circular diffusion area of the remaining viable skin was excised. This tissue was transferred to another centrifuge tube containing $0.1 \mathrm{M}$ ammonium oxalate $(1.3 \mathrm{ml})$ and acetonitrile $(0.7 \mathrm{ml})$. In all cases, the centrifuge tubes were vortexed for $15 \mathrm{~s}$, sonicated for $30 \mathrm{~min}$ and vortexed again for $15 \mathrm{~s}$. Subsequently, each solution was transferred via a $0.2 \mu \mathrm{m}$ PTFE syringe filter into a UPLC vial. In order to quantify transdermal delivery of the drug, $300 \mathrm{ml}$ aliquots of the receptor fluid were taken at baseline (just before foam application) and at $24 \mathrm{~h}$.

\section{UPLC assay}

Quantitative analysis of Minocycline samples involved use of an Acquity UPLC ${ }^{\mathrm{TM}}$ system (Waters Corp., Milford, MA) equipped with a photodiode array detector and an autosampler (G07UPA696M) run at $5^{\circ} \mathrm{C}$. The diluent was a solution of $0.1 \mathrm{M}$ ammonium oxalate, acetonitrile $65,35(\mathrm{v} / \mathrm{v})$. Samples were eluted on a $\mathrm{C}_{18}$ Acquity BEH column $(100 \mathrm{~mm} \times 2.1 \mathrm{~mm} ; 1.7 \mathrm{~mm})$ run at $40^{\circ} \mathrm{C}$. The mobile phase consisted of a mixture of $0.1 \mathrm{M}$ ammonium oxalate, $0.01 \mathrm{M}$ EDTA, dimethylformamide,tetrahydrafuran at a $60,18,12,8$ ratio $(\mathrm{v} / \mathrm{v})$. The elution parameters were a flow rate of $4 \mathrm{ml} / \mathrm{min}$ and an injection volume of $1 \mathrm{ml}$. The detection wavelength was $277 \mathrm{~nm}$. Calibration was achieved by using external standards. The sample retention time was $9 \mathrm{~min}$ and the method's limit of quantitation was $2 \mathrm{mg} / \mathrm{ml}$.

\section{Results and discussion}

\section{TEWL readings}

The skin samples used for the $1 \%$ minocycline studies showed a TEWL of $9.5 \pm 1.40 \mathrm{~g} / \mathrm{m}^{2} / \mathrm{h}$ (mean $\pm \mathrm{SD}$ ) while the skins used in the $4 \%$ minocycline studies showed a TEWL of $10.25 \pm 1.42 \mathrm{~g} / \mathrm{m}^{2} / \mathrm{h}$ (mean \pm
SD). These values do not significantly differ from each other (t-test, $\mathrm{P}$ $=0.38$ ). Moreover, these TEWL values are low enough to indicate that all the test skins were intact in terms of skin barrier function. ${ }^{13}$

\section{Minocycline deposition in skin strata}

Table 1 presents the amounts of $\mathrm{MCH}$ present in each compartment at $24 \mathrm{~h}$. It can be seen that most of the antibiotic remained unabsorbed as residues on the skin surface. Nonetheless, appreciable amounts of $\mathrm{MCH}$ did accumulate in the skin following 24 hours of drug treatment. The total mean amount of $\mathrm{MCH}$ found in the skin was $11.38 \mathrm{mg}$ $\left(\equiv 6.43 \mathrm{mg} / \mathrm{cm}^{2}\right)$ for the $1 \%$ formulation and $108.90 \mathrm{mg}(\equiv 61.52 \mathrm{mg} /$ $\mathrm{cm}^{2}$ ) for the $4 \%$ formulation. The stratum corneum, including its deeper layers, contained $10.60 \pm 4.2 \mu \mathrm{g}$ of the drug, $\left(\equiv 5.99 \mathrm{mg} / \mathrm{cm}^{2}\right)$ for the $1 \%$ formulation and $105.41 \pm 24.98 \mathrm{mg}\left(\equiv 59.55 \mathrm{mg} / \mathrm{cm}^{2}\right)$ for the $4 \%$ formulation. Treatment with the $1 \%$ formulation resulted in a mean viable skin $\mathrm{MCH}$ content of $0.78 \mathrm{mg}\left(\equiv 0.44 \mathrm{mg} / \mathrm{cm}^{2}\right)$. Treatment with the $4 \%$ formulation caused $3.49 \pm 0.92 \mathrm{mg}\left(\equiv 1.97 \mathrm{mg} / \mathrm{cm}^{2}\right)$ to accumulate within the viable skin.

It can be seen that allowing for variations attributable to the differences between individual skin samples tested, the quantity of drug detected in each compartment was approximately proportional to the respective $\mathrm{MCH}$ concentration in the foam. So for example, treatment with $1 \% \mathrm{MCH}$ foam resulted in a mean $\mathrm{MCH}$ content in the viable skin of $0.78 \mu \mathrm{g}$ whereas treatment with the $4 \% \mathrm{MCH}$ foam resulted in this layer exhibiting a mean $\mathrm{MCH}$ content of $3.49 \mu \mathrm{g}$. It is noteworthy that our assay could not detect any $\mathrm{MCH}$ present in the receptor fluid.

In order to determine whether these antibiotic foams would be efficacious, it is necessary to consider that the weight of skin at the delivery area is $\sim 100 \mathrm{mg}$. This implies that following $24 \mathrm{~h}$ of exposure, the $1 \%$ foam delivered a mean $\mathrm{MCH}$ concentration of $\sim 106 \mathrm{mg} / \mathrm{g}$ in the stratum corneum and $\sim 7.8 \mathrm{mg} / \mathrm{g}$ in the viable skin; and exposure to the $4 \%$ foam delivered a mean $\mathrm{MCH}$ concentration of $1,054 \mathrm{mg} / \mathrm{g}$ in the stratum corneum and $\sim 34.9 \mathrm{mg} / \mathrm{g}$ in the viable skin.

According to the literature reports, the minimum inhibitory concentration of $\mathrm{MCH}$ is typically below $4 \mathrm{mg} / \mathrm{ml} .{ }^{14}$ Skin density has been given as $\sim 1 \mathrm{~g} / \mathrm{ml} .{ }^{15}$ Hence, it can be calculated that by $24 \mathrm{~h}$, both formulations delivered sufficient $\mathrm{MCH}$ to the target tissue such that drug concentration values were multiple fold the MIC.

\section{Mass of foam}

When some of these permeation studies were repeated using $500 \mathrm{mg}$ foam, the $\mathrm{MCH}$ concentrations in the viable skin at $24 \mathrm{~h}$ were found to not significantly differ from that achieved using only $20 \mathrm{mg}$ of foam (data not shown). This indicates that the $20 \mathrm{mg}$ finite dose application is just as effective as using an infinite dose.

\section{Distribution of minocycline in pig ear skin by MALDI FTICR imaging.}

Porcine ear skin tissues were treated with Minocycline Foam, FMX101 4\%. The skin tissues were mounted on the Franz cell and $250 \mu \mathrm{g}$ of collapsed foam was applied on $1.7 \mathrm{~cm}^{2}$ surface. The skin membranes had $38^{\circ} \mathrm{C}$ water serving as a receiver fluid on the other side of the membrane. After 24-hour exposure, the skin surfaces were cleansed with soybean oil to remove excess of the formulation and then samples were frozen at $-70^{\circ} \mathrm{C}$.

The frozen skins were cryo-sectioned to obtain $10 \mu \mathrm{m}$ - thick layers, which were mounted on tape and then on ITO slide. 2,5Dihydroxybenzoic acid (2,5-DHB, $40 \mathrm{mg} / \mathrm{mL}$ in MetOH/TFA $0.1 \%$ 
$1,1 \mathrm{v}, \mathrm{v})$ MALDI matrix spiked with d6-Minocycline at $10 \mu \mathrm{M}$ was sprayed on the tissue section with the Suncollect automatic sprayer (Sunchrome, Friedrichsdorf, Germany).

The MALDI analysis was conducted utilizing 7T-MALDI-FTICR (Solarix, Bruker Daltonics, Bremen, Germany). Mass spectra were acquired with a CASI mode (Continuous Accumulation of Selected Ions) of acquisition within the $\mathrm{m} / \mathrm{z} 443-473$ range at $30 \mu \mathrm{m}$ of spatial resolution. Minocycline signal was normalized with d6-Minocycline signal for each pixel in Multimaging software (ImaBiotech, Loos, France). The intensity scale of the Minocyclinewas adjusted to allow the better visualization of the API distribution. An adjacent tissue section was stained with a Hematoxylin-Eosin (H\&E) protocol in order to have a side by side comparison between the molecular distribution and the optical image. As shown in Figure 2, Minocycline was detected in the viable skin, including the epidermis and the upper layers of the dermis. Minocycline was also detected in the hair follicles (Figure 3).

\section{Penetration of minocycline into the pilosebaceous unit in pig ear skin, by fluorescent microscopy}

A pig ear skin area of $10 \mathrm{x} 8 \mathrm{~cm}^{2}$ was marked with a permanent marker. $160 \mathrm{mg}\left(2 \mathrm{mg} / \mathrm{cm}^{2}\right)$ of the FMX101 collapsed formulation was applied with a syringe and distributed homogeneously with a gloved finger. Subsequent to application the substance was left on the skin for a 60-min penetration time, and then biopsy was taken and prepared histological sections of the hair follicles, which were examined using reflectance and fluorescent microscopy. As shown in Figure 4, where reflectance and fluorescent images are superimposed, minocycline has penetrated the pilosebaceous unit, including hair follicles and the sebaceous gland (red areas). The vehicle of FMX101 is hydrophobic, and as such, it is expected to dissolve sebum upon application to the skin, which may explain the targeting of the $\mathrm{MCH}$ penetration into the pilosebaceous unit.

\section{Conclusion}

The results showed that topical administration of this novel $\mathrm{MCH}-$ loaded foam delivered high amounts of minocycline into skin so as to effectively treat conditions such as acne and rosacea, as well as impetigo. Furthermore, minocycline was detected in the pilosebaceous unit, including the hair follicle and the sebaceous gland. Of note, there was no systemic penetration of $\mathrm{MCH}$. These results corroborate with the high efficacy of minocycline foam in the treatment of acne, rosacea and impetigo, as recently demonstrated in clinical trials.

\section{Acknowledgements}

The images of Figures $2 \& 3$ were provided by ImaBiotech, Lille, France.

The authors thank Prof. Dr. Juergen Lademann of ChariteCentrum fur InnereMedizin und Dermatologie, Berlin for providing the fluorescent images of Figure 4.
The development of FMX101 was supported by the BIRD Foundation (www.birdf.com).

\section{Conflicts of Interset}

None.

\section{References}

1. Kircik LH. Doxycycline and minocycline for the management of acne: a review of efficacy and safety with emphasis on clinical implications. $J$ Drugs Dermatol.2010;9(11):1407-1411.

2. Leive L, Telesetsky S, Coleman WG, et al. Tetracyclines of various hydrophobicities as a probe for permeability of Escherichia coli outer membrane. Antimicrob Agents Chemother. 1984;25(5):539-544.

3. Zhao Y, Jones SA, Brown MB. Dynamic foams in topical drug delivery. J Pharm Pharmacol. 2010;62(6):678-684.

4. Tamarkin D. A unique topical drug delivery system. Int J Cosmet Sci. 2012;24:384.

5. Tamarkin D. Foam: A Unique Delivery Vehicle for Topically Applied Formulations. In: Dayan N (Eds.), Formulating Topical Applications - a Practical Guide, Carol Stream, IL: CT Books, USA. 2013; pp. 233-260.

6. Tamarkin DSurfactant-Free Water-Free Foamable Compositions, Breakable Foams and Gels and Their Uses. International Patent WO2011039637. 2011

7. Arzhavitina A, Steckel H. Foams for pharmaceutical and cosmetic application. Int J Pharm. 2010;394(1-2):1-17.

8. Tamarkin D, Friedman D, Shemer A. Emollient foam in topical drug delivery. Expert Opin Drug Deliv. 2006;3(6):799-807.

9. Cash K, Quigley MO. The vehicle found in ketoconazole foam $2 \%$ is preferred by patients with mild to severe seborrheic dermatitis over other vehicles, regardless of gender, age or ethnicity. J Am Acad Dermatol. 2008;58(2):AB92.

10. Kahanek N, Gelbard C, Hebert A. Desonide: a review of formulations, efficacy and safety. Expert OpinInvestig Drugs 2008;17(7):1097-1104.

11. Frum Y, Khan GM, Sefcik J, et al. Towards a correlation between drug properties and in vitro transdermal flux variability. Int $J$ Pharm. 2007;336(1):140-147.

12. Touitou E, Meidan VM, Horwitz E. Methods for quantitative determination of drug localized in the skin. J Control Rel. 1998; 56(13): $7-21$.

13. Elmahjoubi E, Frum Y, Eccleston GM, et al. Transepidermal water loss for probing full-thickness skin barrier function: correlation with tritiated water flux, sensitivity to punctures and diverse surfactant exposures. Toxicol In Vitro. 2009;23(7):1429-1435.

14. Reynolds JE. Martindale: The Extra Pharmacopoeia. In: Reynolds JEF (Eds.), Royal Pharmaceutical Society, (31st edn), London, UK. 1996; pp. 829-830.

15. http://physics.info/about/ 